\title{
Evaluation of TGF- $\beta 1$, CCL5/RANTES and sFas/Apo-1 urine concentration in children with ureteropelvic junction obstruction
}

\author{
Aleksandra Gawłowska-Marciniak ${ }^{1}$, Jerzy K. Niedzielski²
}

\begin{abstract}
1Department of Pediatric Surgery and Oncology, University Children's Hospital No. 4, Medical University of Lodz, Poland

2Department of Pediatric Surgery and Urology, University Children's Hospital No. 4, Medical University of Lodz, Poland
\end{abstract}

Submitted: 11 August 2012

Accepted: 26 August 2012

Arch Med Sci 2013; 9, 5: 888-894

DOI: $10.5114 /$ aoms.2013.36912

Copyright @ 2013 Termedia \& Banach

\begin{abstract}
Introduction: The aim of this study was to evaluate changes in expression of soluble biomarkers tumor factor growth- $\beta 1$ (TGF- $\beta 1$ ), CCL5/RANTES, and sFas/Apo-1 in the urine of patients undergoing ureteropyeloplasty for ureteropelvic junction (UPJ) obstruction. These factors are connected with different processes ongoing in the obstructive uropathy. If their urine concentrations correlate with AP diameter of the renal pelvis and differential function of the affected kidney, they can be helpful in making a decision on corrective surgery.

Material and methods: Creatinine, TGF- $\beta 1$, CCL5/RANTES, and sFas/Apo- 1 levels were measured in the urine from the bladder and renal pelvis of 45 patients undergoing ureteropyeloplasty and from bladders of 25 patients undergoing inguinal herniorrhaphy.

Results: Levels of examined biomarkers were higher in the renal pelvis and bladder of children with UPJ obstruction as compared to controls: TGF- $\beta 1$ in older children and adolescents $(p<0.05)$, CCL5/RANTES in the youngest and older children $(p<0.05)$, and sFas/Apo-1 in all patients $(p<0.05)$. Twelve months after surgery their levels in the bladder decreased: TGF- $\beta 1$ in younger and older children $(p<0.05), C C L 5 /$ RANTES in the youngest patients and adolescents $(p<0.05)$, and sFas/Apo-1 in the youngest and older children $(p<0.05)$. A significant decrease in the AP diameter of the renal pelvis post-operatively $(32.09 \mathrm{~mm}$ vs. $18.72 \mathrm{~mm})(p<0.01)$ and significant improvement in renal function $(36.94 \%$ vs. $42.76 \%)(p<0.05)$ were observed in the examined group.

Conclusions: Mean TGF- $\beta 1$, CCL5/RANTES, and sFas/Apo- 1 urine levels are significantly increased in patients with UPJ and decreased 1 year after ureteropyeloplasty. Bladder concentrations of examined factors may be clinically useful markers of obstruction.
\end{abstract}

Key words: obstructive uropathy, biomarkers, renal ultrasonography, renoscintigraphy.

\section{Introduction}

Ureteropelvic junction obstruction diagnosed prenatally occurs in $1: 150$ to $1: 1200$ pregnancies [1, 2]. Hydronephrosis can be a result of anatomical or functional obstruction. It is diagnosed almost twice as often in boys and can affect either one kidney (most often the left) or both kidneys [3-7].

\author{
Corresponding author: \\ Aleksandra \\ Gawłowska-Marciniak PhD \\ Department of Pediatric \\ Surgery and Oncology \\ Medical University of Lodz \\ 36/50 Sporna St \\ 91-738 Lodz, Poland \\ Phone/fax: +48 426177705 \\ E-mail: agawlowska@mnc.pl
}


Increasing pressure in the renal pelvis stimulates the renin-angiotensin system (RAS), which, in turn, stimulates the expression of tumor necrosis factor $\beta 1$ (TGF- $\beta 1$ ), the cytokine responsible for interstitial fibrosis in the affected kidney [8-10]. A number of factors associated with obstructive uropathy, such as hypoxia, ischemia, cytokines, growth factors and angiotensin II, lead to apoptosis of tubular epithelial cells [7]. Obstructive uropathy impairs the growth of the developing kidney and is still the most important cause of chronic renal insufficiency in children $[1,4,11,12]$.

Transforming growth factor $\beta 1$ is a multifunctional cytokine crucial for embryonic development and for repair and regeneration after tissue injury [13]. Transforming growth factor $\beta 1$ plays a critical role in the regulation of collagen synthesis in the extracellular matrix and in the synthesis of $\alpha$-actin of smooth muscles in the cells of the mesangium. Transforming growth factor $\beta 1$ is detectable in the urine of patients with pathological conditions of the urinary tract $[8,9,14,15]$.

Regulated on activation normal T-cell expressed and secreted (RANTES) is a chemokine from the $\beta$ or CC subfamily, secreted by macrophages and T lymphocytes [10, 12]. CCL5/RANTES is responsible for the interstitial inflammatory changes in various types of human glomerular diseases by activating the migration of cells $[15,16]$. However, its role in obstructive uropathy is not clear.

sFas/Apo-1 (CD95) belongs to the tumor necrosis factor superfamily of cell membrane receptors. Soluble Fas, detectable in serum and urine, can antagonize cell-surface Fas function and suppress apoptosis of cells by blocking the Fas ligand [17]. Serum and urinary excretion of sFas were observed in patients with cancers, proliferative glomerulonephritis and idiopathic pulmonary fibrosis [18].

The aim of this study was to evaluate changes in expression of soluble biomarkers TGF- $\beta 1$, CCL5/ RANTES, and sFas/Apo-1 in the urine of patients undergoing ureteropyeloplasty for ureteropelvic junction (UPJ) obstruction. Accordingly, measurements were obtained of the TGF- $\beta 1$, CCL5/RANTES and Fas (sFas/Apo-1) levels in children with and without UPJ obstruction in order to 1) assess their correlation with the anterior-posterior (AP) diameter of the renal pelvis measured by ultrasound, 2) assess by renoscintigraphy their correlation with the differential function of the obstructed kidney before and 1 year after surgery, 3) determine whether the levels of the biomarkers in the urine change after correction of the hydronephrosis. We choose these three biomarkers because each of them is connected with a different process ongoing in the obstructed kidney. If urine concentration of any of these biomarkers correlates with AP diameter of the renal pelvis and the differential function of the kidney, it can be helpful in making a decision on the right time for corrective surgery.

\section{Material and methods}

Between 2002 and 2006, 45 consecutive patients (30 boys and 15 girls) aged 1 month to 18 years (mean $8.4 \pm 5.66$ years) underwent surgery for unilateral obstructive hydronephrosis. The left kidney was the most commonly affected (33/45 - 73.3\%). We divided the children into three age subgroups based on stages of kidney maturation (Table I). Unilateral UPJ obstruction was diagnosed preoperatively by ultrasound in all 45 patients, intravenous pyelogram (IVP) in 29 patients (64.4\%) and dynamic renoscintigraphy in 31 patients $(68.9 \%)$. The studies were repeated 12 months post-operatively. Renal obstruction was confirmed with dynamic renoscintigraphy, using technetium labeled diethylenetriaminepentaacetic acid (DTPA). Prolonged half-time drainage (20 min or more), differential renal function (DRF) less than $40 \%$ and/or an obstructive washout curve pattern during the diuretic phase were used as diagnostic criteria for obstruction. Intravenous pyelogram criteria for obstruction were based on a greater than 1-hour ureteral filling time, renal pelvic and

Table I. Age, sex and number of patients with hydronephrosis and of controls

\begin{tabular}{|c|c|c|c|c|c|c|c|}
\hline \multirow{2}{*}{$\begin{array}{l}\text { Age } \\
\text { subgroups } \\
\text { [years] }\end{array}$} & \multicolumn{4}{|c|}{ Obstructed children } & \multirow{2}{*}{$\begin{array}{l}\text { Hydronephrosis } \\
\text { left-sided }\end{array}$} & \multicolumn{2}{|c|}{ Controls } \\
\hline & $\begin{array}{l}\text { Mean age } \\
\text { (SD) [years] }\end{array}$ & $\mathrm{F}$ & $M$ & $\begin{array}{l}\text { Total } \\
n(\%)\end{array}$ & & $\begin{array}{l}\text { Mean age } \\
\text { (SD) [years] }\end{array}$ & $\begin{array}{c}\text { Patients } \\
n(\%)\end{array}$ \\
\hline $\begin{array}{l}\text { Young children } \\
(0-2.0)\end{array}$ & $0.56(0.56)$ & 1 & 6 & $7(15.6)$ & 4/7 (57.1) & $1.48(0.71)$ & $5(20)$ \\
\hline $\begin{array}{l}\text { Older children } \\
(2.1-10)\end{array}$ & $5.99(2.70)$ & 8 & 12 & $20(44.4)$ & $16 / 20(80)$ & $5.12(1.5)$ & $5(20)$ \\
\hline $\begin{array}{l}\text { Adolescents } \\
(10.1-18)\end{array}$ & $14.16(2.74)$ & 6 & 12 & $18(40)$ & $13 / 18(72.2)$ & $12.05(1.11)$ & $15(60)$ \\
\hline Total & $8.41(5.66)$ & 15 & 30 & $45(100)$ & $33 / 45(73.3)$ & $5.78(3.73)$ & $25(100)$ \\
\hline
\end{tabular}

F-female, $M$ - male, SD - standard deviation 
calyceal dilatation, and renal cortical index $(\mathrm{RCl})$ greater than 0.4 [19].

All patients with obstruction underwent open dismembered ureteropyeloplasty. A renal pelvis urine sample was obtained by needle aspiration before the ureteropyeloplasty was performed. A bladder urine sample was obtained via spontaneous voiding $1 \mathrm{~h}$ before operation and 12 months post-operatively.

The control group consisted of 25 healthy patients, aged 7 months to 13 years (mean age 5.8 \pm 3.73 years) who underwent inguinal hernia repair in the years 2002-2005. They were divided into three age subgroups corresponding with the subgroups of obstructive patients (Table I). These children provided bladder urine samples by spontaneous voiding $1 \mathrm{~h}$ before surgery.

Creatinine levels were determined in all samples of urine using a clinical commercial laboratory. Samples were centrifuged (2000 g) for $10 \mathrm{~min}$ at $+4^{\circ} \mathrm{C}$, and stored at $-20^{\circ} \mathrm{C}$ until the moment of assessment. Concentrations of examined factors (TGF- $\beta 1$, CCL5/ RANTES, sFas/Apo-1) were measured in duplicate using immunoenzymatic (ELISA) commercial kits (catalog no. KAC1681, KHC1032, KHS9502, BIOSOURCE INT., Camarillo, CA, USA). The results of all 3 cytokine concentrations were related to the urine creatinine.

Informed consent was obtained from parents of patients of the examined and control groups.

\section{Statistical analysis}

Shapiro-Wilk $W$ test showed the lack of normal distribution of the examined biomarker values; therefore nonparametric tests, Mann-Whitney $U$ test and Wilcoxon test, were used for statistical analysis. Renal pelvis antero-posterior diameter values had normal distribution and were compared by t-test. Statistics PL 6.0 for Windows was used for statistical analysis.

\section{Results}

At the time of the procedure the renal pelvic levels of TGF- $\beta 1$ were significantly higher than controls in older children $(3869.00 \pm 1062.34 \mathrm{pg} / \mathrm{mg} \mathrm{Cr}$ vs. $1370.29 \pm 322.70 \mathrm{pg} / \mathrm{mg} \mathrm{Cr} ; p<0.05)$ and in adolescents $(1283.54 \pm 632.12 \mathrm{pg} / \mathrm{mg} \mathrm{Cr}$ vs. 481.50 $\pm 139.57 \mathrm{pg} / \mathrm{mg} \mathrm{Cr}$ ). Tumor growth factor- $\beta 1$ urine concentrations in the renal pelvis (4495.18 \pm 818.01 $\mathrm{pg} / \mathrm{mg} \mathrm{Cr}$ ) and bladder (4652.33 $\pm 756.16 \mathrm{pg} / \mathrm{mg} \mathrm{Cr}$ ) of younger children were significantly higher $(p<0.001)$ than in adolescents (respectively 1283.54 $\pm 632.12 ; 854.43 \pm 196.65 \mathrm{pg} / \mathrm{mg} \mathrm{Cr}$ ). Mean bladder concentration of TGF- $\beta 1$ before the operation differed significantly between younger children (4652.33 $\pm 756.16 \mathrm{pg} / \mathrm{mg} \mathrm{Cr}$ ), older ones (1727.09 $\pm 431.17 \mathrm{pg} / \mathrm{mg} \mathrm{Cr} ; p<0.01)$ and adolescents (854.43 $\pm 196.65 \mathrm{pg} / \mathrm{mg} \mathrm{Cr} ; p<0.001)$. Mean bladder concentration of TGF- $\beta 1$ decreased significantly 12 months after surgery in younger (4652.33 \pm 756.16 $\mathrm{pg} / \mathrm{mg}$ Cr vs. $595.44 \pm 79.65 \mathrm{pg} / \mathrm{mg} \mathrm{Cr} ; p<0.05)$ and older patients $(1727.09 \pm 431.17 \mathrm{pg} / \mathrm{mg}$ Cr vs. 602.84 $\pm 116.29 \mathrm{pg} / \mathrm{mg} \mathrm{Cr} ; p<0.05$ ) (Figure 1).

At the time of the procedure the renal pelvic levels of CCL5/RANTES were significantly higher compared with controls, in the youngest children (780.12 $\pm 653.56 \mathrm{pg} / \mathrm{mg} \mathrm{Cr}$ vs. $351.86 \pm 110.19 \mathrm{pg} / \mathrm{mg} \mathrm{Cr}$; $p<0.05)$ and in older children (312.23 $\pm 92.06 \mathrm{pg} / \mathrm{mg}$ Cr vs. $204.03 \pm 42.47 \mathrm{pg} / \mathrm{mg} \mathrm{Cr} ; p<0.05)$. The CCL5/ RANTES level in the renal pelvis $(780.12 \pm 653.56$ $\mathrm{pg} / \mathrm{mg} \mathrm{Cr})$ and bladder $(768.33 \pm 293.18 \mathrm{pg} / \mathrm{mg} \mathrm{Cr})$ of the youngest patients was two times higher than levels measured in older children (respectively 312.23 $\pm 92.06 ; 188.40 \pm 46.90 \mathrm{pg} / \mathrm{mg} \mathrm{Cr} ; p<0.05$ ) and five times higher than in adolescents (respectively 150.63 $\pm 91.63 ; 135.19 \pm 58.35 \mathrm{pg} / \mathrm{mg} \mathrm{Cr} ; p<0.01)$. The CCL5/ RANTES level in the bladder decreased 12 months after ureteropyeloplasty in the youngest children $(50.68 \pm 24.27 \mathrm{pg} / \mathrm{mg} \mathrm{Cr} ; p<0.05)$ and in adolescents (39.57 $\pm 13.33 \mathrm{pg} / \mathrm{mg} \mathrm{Cr} ; p<0.05)$ (Figure 2).

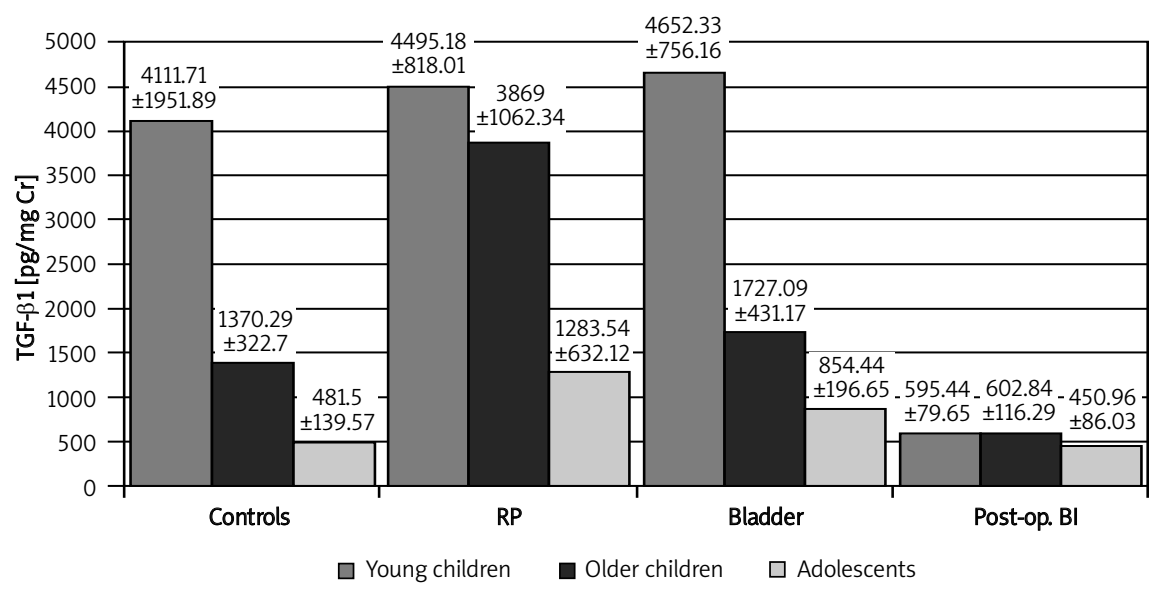

Figure 1. Mean urine concentration of TGF- $\beta 1$ in renal pelvis (RP), bladder, and bladder 1 year after operation (Post-op. Bl) in consecutive age subgroups and controls Results presented as mean $\pm S D$ 


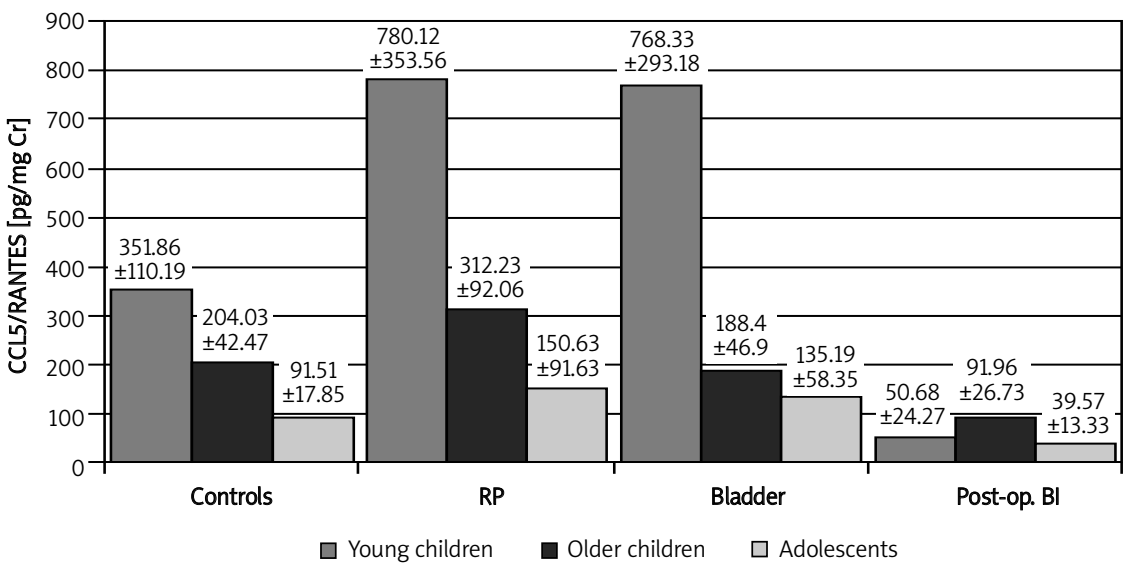

Figure 2. Mean urine concentration of CCL5/RANTES in renal pelvis (RP), bladder, and bladder 1 year after operation (Post-op. $\mathrm{Bl}$ ) in consecutive age subgroups and controls Results presented as mean $\pm S D$

At the time of the procedure the renal pelvic and bladder levels of sFas/Apo-1 were significantly elevated compared with controls, in the youngest (respectively $3.19 \pm 1.42 ; 2.86 \pm 0.55$ vs. $1.07 \pm 0.60$ $\mathrm{ng} / \mathrm{mg} \mathrm{Cr} ; p<0.05)$, older children (3.17 $\pm 1.64 ; 3.24$ \pm 1.33 vs. $0.98 \pm 0.18 \mathrm{ng} / \mathrm{mg} \mathrm{Cr} ; p<0.05)$ and in adolescents (1.06 $\pm 0.64 ; 1.00 \pm 0.35$ vs. $0.33 \pm 0.04$ $\mathrm{ng} / \mathrm{mg} \mathrm{Cr} ; p<0.05)$. Before the surgery the bladder levels of sFas/Apo-1 were most elevated in older children $(3.24 \pm 1.33 \mathrm{ng} / \mathrm{mg} \mathrm{Cr}$ ). The sFas/Apo-1 bladder levels decreased 12 months after ureteropyeloplasty in the youngest $(1.45 \pm 0.47 \mathrm{ng} / \mathrm{mg} \mathrm{Cr}$; $p<0.05)$ and in older patients $(1.12 \pm 0.31 \mathrm{ng} / \mathrm{mg} \mathrm{Cr}$; $p<0.05)$. One year after surgery the levels of sFas/Apo-1 measured in urine obtained from the bladder in all operated children normalized to the level of controls (Figure 3).

The mean antero-posterior (AP) diameter of the renal pelvis decreased significantly 1 year after the operation in the entire examined group (32.09 $\pm 14.98 \mathrm{~mm}$ vs. $18.78 \pm 8.34 \mathrm{~mm} ; p<0.01$ ), as well as in the consecutive ge subgroups $(p<0.05$, $p<0.05, p<0.01$ ). The greatest AP diameter of the renal pelvis before and after surgery was found in adolescents (39.12 $\pm 16.34 \mathrm{~mm}$ vs. $23.75 \pm 8.45 \mathrm{~mm}$ ). No correlation was found between AP diameter of the renal pelvis and the bladder urine levels of examined factors before or 12 months after surgery.

The mean differential function of the affected kidney evaluated by renoscintigraphy improved significantly 1 year after the operation in the entire examined group (36.94 $\pm 13.81 \%$ vs. $42.76 \pm 11.17 \%$; $p<0.05)$, and in older children $(39.5 \pm 11.91 \%$ vs. $44.4 \pm 9.23 \% ; p<0.05)$. The pre-operative function of the obstructed kidney in adolescents was the worst in the entire group $(30.27 \pm 12.81 \%)$ and it did not reach the normal range of values postoperatively (35.89 $\pm 12.95 \%)$. No correlation was found between the differential function of the affected kidney and the bladder urine levels of

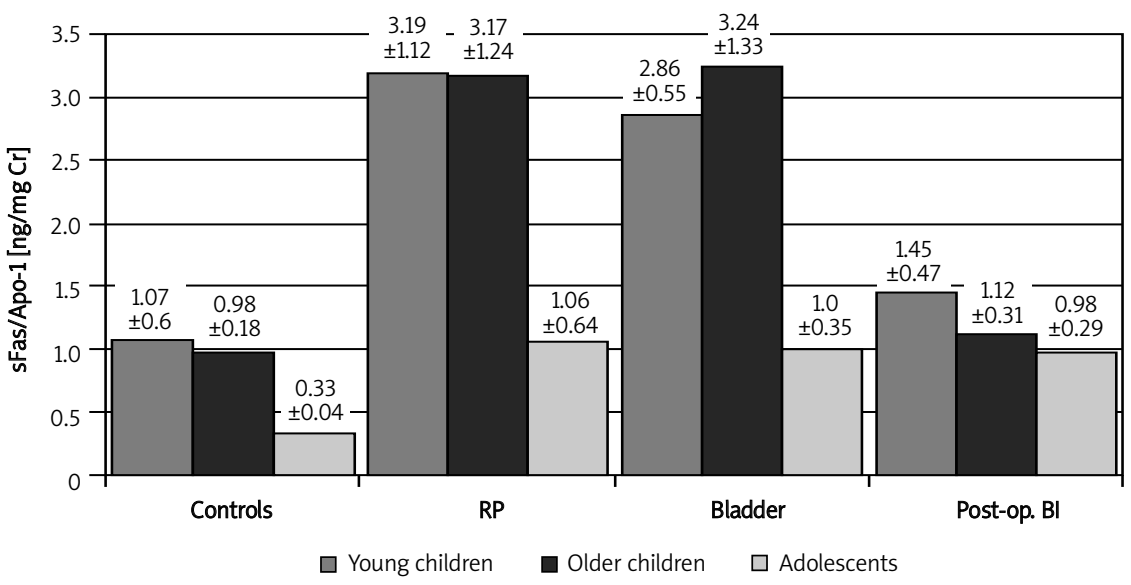

Figure 3. Mean urine concentration of sFas/Apo-1 in renal pelvis (RP), bladder, and bladder 1 year after operation (Post-op. $\mathrm{Bl}$ ) in consecutive age subgroups and controls Results presented as mean \pm SD 
examined factors before or 1 year after the operation.

\section{Discussion}

The decision of surgical treatment for hydronephrosis is still based on the results of imaging methods. Currently, approximately $80 \%$ of hydronephrosis diagnoses are established in children within the first year of life by ultrasound $[3,20]$. Surgical repair of obstruction is the optimal and most effective treatment in $93-96 \%$ of cases [4, 6]. Despite the functional release of obstruction, chronic nephropathy may persist and sometimes progress through activation of profibrotic signaling. However, a study of Rosen et al. based on the results of renal biopsies performed in children with congenital UPJ obstruction undergoing pyeloplasty revealed in most of them a relatively wellmaintained parenchyma with mainly glomerular changes [21].

In our study we demonstrated that in children with upper urinary tract obstruction, TGF- $\beta 1$ has the highest urine concentration in the renal pelvis, which is convergent with the results of research from Chicago and Mansoura [8, 9]. However, in our patients TGF- $\beta 1$ concentration in the bladder 1 year after surgery was lower than values observed in controls, especially in children under 10 years. Furness et al. [8] and Taha et al. [22] reported that the renal pelvis and bladder levels of TGF- $\beta 1$ were significantly higher in younger patients. Chevalier tried to explain this fact by suggesting that the kidney, just after nephrogenesis, is more sensitive to the injury caused by the increasing pressure in the renal pelvis, while in older children, resilience of the tubular cells decreases [2]. Although we observed the highest levels of TGF- $\beta 1$ in children under 2 years, significantly elevated levels were also found in older children and adolescents. El-Sherbiny et al. and Taha et al. observed a decrease of urine bladder level of TGF- $\beta 1$ with every month after surgery $[9,22]$. The low concentration of TGF- $\beta 1$, which we observed in all children 1 year post-operatively, can be explained by aggravated suppression of macrophage infiltration (macrophages being an important source of TGF- $\beta 1$ production).

CCL5/RANTES levels show similar dynamics of change over time as were observed with levels of TGF- $\beta 1$. The current study revealed the highest mean concentration of CCL5/RANTES from the renal pelvis in patients under 10 years, which indicates its local production in the obstructed kidney. These values were higher than in controls under 10 years, which is an important clinical observation. The increasing expression of CCL5/RANTES and its receptors CCR1, 3 and 5 was confirmed in experimental hydronephrosis in mice [23]. Shortly after injury renal cells release chemokines which mediate lymphocyte infiltration during the initiation phase of renal disorder. The infiltrating leukocytes secrete more chemokines and cytokines responsible for fibrosis of the kidney [10, 12, 24]. Levels of this chemokine in our patients significantly decreased one year after ureteropyeloplasty. After relief of obstruction the expression of CCL5/RANTES is decreased. However, the fibrotic changes were reported to remain despite low levels of CCL5/ RANTES 12 months after surgery [10].

The mean urine concentration of soluble Fas (sFas) was markedly elevated at the time of the operation in the renal pelvis and bladder of all examined children, which proves the local production of this factor in the kidney. Its concentration was diluted in the bladder urine, but was still higher than in controls. We observed its highest bladder level in children operated before 10 years of age. sFas urine concentration is the resultant of cell apoptosis and fibrogenesis, which are not present in the early stage of nephropathy. The sFas/Apo-1 is produced as an alternatively spliced variant of Fas, and its release can be regulated by different mechanisms. Some of them are activated in fibroblasts in which synthesis is strongly stimulated by TGF- $\beta 1$ [17]. One year after ureteropyeloplasty, the mean sFas/Apo-1 concentration normalized in the investigated group to the level of controls. It is difficult to say how important is the role that sFas/ Apo-1 plays in fibrogenesis in obstructive uropathy. The main investigated factor responsible for that process is TGF- $\beta 1$, but sFas sustains fibrogenesis through disturbing cell apoptosis [18].

Progressive fibrosis and apoptosis affect not only the kidney, but the collecting system as well [17]. The AP diameter of the renal pelvis, measured by ultrasound, is a basic examination in obstructive uropathy. Because of availability of equipment and the non-invasive character of the study, this method is used for screening and monitoring the size of the renal pelvis pre- and post-operatively. We found a weak and non-significant correlation between AP diameter of renal pelvis and sFas/Apo-1 bladder urine concentration before and after surgery in the youngest children. The correlation would probably become significant with a larger number of patients.

Renoscintigraphy is used to assess renal function, secretion and excretion of urine. We found no correlation between urine levels of the studied factors and differential function of the affected kidney. Similar findings were reported by El-Sherbiny et al. in relation to TGF- $\beta 1$ [9].

Our study showed that all three measured factors were significantly elevated in the urine obtained from the renal pelvis and bladder of children with UPJ obstruction as compared to nonobstructed healthy controls. These levels decreased 
after pyeloplasty. This observation may be useful as an additional tool to monitor hydronephrosis during the first 2 years of life in cases with stable diameter of the renal pelvis and renal mass. We observed that urine concentrations of examined biomarkers vary with the age of children, both obstructed and controls. The results were similar to those reported by Lee et al. [25].

Although reports in 2008 and 2010 on a new proteomic urine test revealed a new decisive tool in children with UPJ obstruction [25, 26], further longitudinal studies on TGF- $\beta 1$, CCL5/RANTES, and sFas/Apo-1 urine concentrations are needed. Our data strongly suggest utility of measuring urine biomarkers as a clinically important tool in evaluation of hydronephrosis in children under 10 years.

The limitation of the present study, in our opinion, was the number of patients in the consecutive age subgroups, which influenced the statistical correlations.

In conclusion, the data show that the TGF- $\beta 1$, CCL5/RANTES, and sFas/Apo-1 urine concentrations are significantly increased before the corrective operation in patients with hydronephrosis, as compared with the healthy patients. The bladder urine levels normalized 1 year after corrective surgery. Our findings indicate the usefulness of TGF- $\beta 1$, CCL5/RANTES, and sFas/Apo-1 urine concentrations as markers of renal function in children with obstructive uropathy under 10 years of age, but they need further investigation on larger groups of patients.

\section{Acknowledgments}

The authors thank Dr. John N. Schullinger of Morgan Stanley Children's Hospital of New York for reviewing the manuscript.

Financial sources: the KBN (National Scientific Research Committee) grant No. 2 PO5E 07228

Committee of Bioethics of University School of Medicine in Lodz: Permission No. RNN/122/03/KE

All biomarker data are presented in tables on the website http://usk4.umed.lodz.pl/pliki/urologia/ Tables-2-4.pdf

\section{References}

1. Elder JS. Antenatal hydronephrosis. Pediatr Clin North Am 1997; 44: 1299-332.

2. Chevalier RL, Thornhill BA, Chang AY, et al. Recovery from release of ureteral obstruction in the rat: relationship to nephrogenesis. Kidney Int 2002; 61: 2033-43.

3. Lee RS, Cendron M, Kinnamon DD, et al. Antenatal hydronephrosis as a predictor of postnatal outcome: a metaanalysis. Pediatrics 2006; 118: 586-93.

4. Carr MC, El-Ghoneimi A. Anomalies and surgery of the ureteropelvic junction in children. In: Campbell-Walsh urology. Wein AJ, Kavoussi LR, Novick AC (eds). Saunders, Philadelphia 2007; 3359.
5. Gawłowska A, Niedzielski J. Obstructive uropathy in children - chosen aspects. Przegl Pediatr 2003; 33: 282-5.

6. Johnston J, Evans J, Glassberg K, et al. Pelvic hydronephrosis in children: a review of 219 personal cases. J Urol 1977; 117: 97-101.

7. Choi YJ, Baranowska-Daca E, Nguyen V, et al. Mechanism of chronic obstructive uropathy: increased expression of apoptosis-promoting molecules. Kidney Int 2000; 58: 1481-91.

8. Furness III PD, Maizels M, Han SW, et al. Elevated bladder urine concentration of transforming growth factor-beta1 correlates with upper urinary tract obstruction in children. J Urol 1999; 162: 1033-6.

9. El-Sherbiny MT, Mousa OM, Shokeir AA, et al. Role of urinary transforming growth factor-betal concentration in the diagnosis of upper urinary tract obstruction in children. J Urol 2002; 168: 1798-800.

10. Anders HJ, Vielhauer V, Schlöndorff D. Chemokines and chemokine receptors are involved in the resolution or progression of renal disease. Kidney Int 2003; 63: 401-15.

11. Chung KH, Chevalier RL. Arrested development of the neonatal kidney following chronic ureteral obstruction. J Urol 1996; 155: 1139-44.

12. Sereger S, Nelson PJ, Schlöndorff D. Chemokines, chemokine receptors and renal disease: from basic science to pathophysiologic and therapeutic studies. J Am Soc Nephrol 2000; 11: 152-76.

13. Kulach A, Dabek J, Wilczok T, Gasior Z. Changes in transforming growth factor beta; and its receptors' mRNA expression in monocytes from patients with acute coronary syndromes. Arch Med Sci 2010; 6: 526-32.

14. Junker U, Haufe C, Nuske K, et al. Elevated plasma TGFbeta1 in renal diseases: cause or consequence? Cytokine 2000; 12: 1084-91.

15. Matsell D, Tarantal A. Experimental models of fetal obstructive nephropathy. Pediatr Nephrol 2002; 17: 470-6.

16. Wolf G, Ziyadeh FN, Thaiss F, et al. Angiotensin II stimulates expression of the chemokine RANTES in rat glomerular endothelial cells. Am Soc Clin Invest 1997; 100: 1047-58.

17. Sano H, Asano K, Minatoguchi S, et al. Plasma soluble Fas and soluble Fas ligand in chronic glomerulonephritis. Nephron 1998; 80: 153-61.

18. Bühling F, Wille A, Röcken C, et al. Altered expression of membrane-bound and soluble CD95/Fas contributes to the resistance of fibrotic lung fibroblasts to FasL induced apoptosis. Respir Res 2005; 17: 6-37.

19. Vuorinen P, Pyykonen L, Anttila P. A renal cortical index obtained from urography films; a preliminary report. $\mathrm{Br}$ J Radiol 1960; 33: 622-6.

20. Wiener JS, O'Hara SM. Optimal timing of initial postnatal ultrasonography in newborns with prenatal hydronephrosis. J Urol 2002; 168: 1826-9.

21. Rosen S, Peters CA, Chevalier RL, et al. The kidney in congenital ureteropelvic junction obstruction: a spectrum from normal to nephrectomy. J Urol 2008; 179: 1257-63.

22. Taha MA, Shokeir AA, Osman HG, et al. Pelvi-ureteric junction obstruction in children: the role of urinary transforming growth factor betal and epidermal growth factor. BJUI 2007; 99: 899-903.

23. Vielhauer V, Anders HJ, Mack M, et al. Obstructive nephropathy in the mouse: progressive fibrosis correlates with tubulointerstitial chemokine expression and accumulation of CC chemokine receptor 2- and 5-positive leukocytes. J Am Soc Nephrol 2001; 12: 1173-87. 
24. Baer PC, Koziolek M, Fierlbeck W, et al. CC-Chemokine RANTES is increased in serum and urine in the early posttransplantation period of human renal allograft recipients. Kidney Blood Press Res 2005; 28: 48-54.

25. Lee RS, Monigarri F, Lutchman M, et al. Temporal variations of the postnatal rat urinary proteome as a reflection of systemic maturation. Proteomics 2008; 8: 1097-112.

26. Drube J, Zurbig P, Schiffer E, et al. Urinary proteome analysis identifies infants but not older children requiring pyeloplasty. Pediatr Nephrol 2010; 25: 1673-8. 